\title{
Regiospecific Synthesis of N2-aryl 1,2,3-Triazoles from 2,5-disubstituted Tetrazoles via Photochemically Generated Nitrile Imine Intermediates
}

Sam Stewart ${ }^{\mathrm{a}}$, Robert Harris*a ${ }^{\mathrm{a}}$, Craig Jamieson* ${ }^{\mathrm{b}}$.

${ }^{a}$ GlaxoSmithKline Medicines Research Centre, Gunnels Wood Road, Stevenage, Hertfordshire, SG1 2NY

${ }^{\mathrm{b}}$ University of Strathclyde, Department of Pure and Applied Chemistry, Thomas Graham Building, 295 Cathedral Street, Glasgow, G1 $1 \mathrm{XL}$

E-mail: Robert.M.Harris@ gsk.com; Craig.Jamieson@strath.ac.uk

Received: The date will be inserted once the manuscript is accepted.

Abstract: The synthesis of N2-aryl 1,2,3-triazoles from 2,5disubstituted tetrazoles was achieved under photochemical conditions. This simple and mild one step reaction provides regiospecific access to 2,4,5-substituted 1,2,3-triazoles via a nitrile imine intermediate. Syntheses of alkyl and heterocylic derivatives were also investigated.

Key words: Photochemistry, Regioselectivity, Hydrazonyl Chloride, Triazole, Indazole

1,2,3-triazoles are an important class of heterocycles due to a number of useful properties. N2-alkyl and acyl 1,2,3-triazoles act as PPAR agonists ${ }^{1}$ and as selective CB1 receptor antagonists. ${ }^{2}$ N2-aryl 1,2,3-triazoles have application as $\beta_{3}$-Adrenergic receptor agonists; ${ }^{3}$ but more uniquely, have photonic properties which make them suitable as biocompatible UV/blue-light emitting dyes ${ }^{4}$ and inhibitors of polymer degradation. ${ }^{5}$ However, issues of regioselectivity between the $N 1$ and $N 2$ position means that the synthesis of $N 2$-substituted 1,2,3-triazoles remains a challenge. Herein, we will focus on synthesis of N2-aryl 1,2,3-triazoles.

A) Synthesis of N2-aryl 1,2,3-triazoles by post-triazole arylation

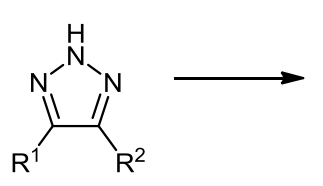

1

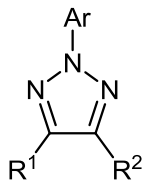

2

B) Synthesis of N2-aryl 1,2,3-triazoles via bis(arylhydrazones)<smiles>[R]/C(=N/N[Al])N/N=C\[Al]</smiles><smiles>C=C</smiles><smiles></smiles><smiles>[R]c1nn([Al])nc1[R]</smiles>

Scheme 1 Common routes to $N 2$-aryl 1,2,3-triazoles

N2-aryl 1,2,3-triazoles 2 are synthesized via two main pathways: A) arylation of $\mathrm{NH}-1,2,3$-triazoles $\mathbf{1}$ or $\mathrm{B}$ ) rearrangement of bis(arylhydrazones) $\mathbf{3}$ via 1,2,3triazolium 1-aminides 4 (Scheme 1).

Shi et. al. reported regioselective copper catalysed, or $\mathrm{S}_{\mathrm{N}} \mathrm{Ar}$ mediated, N2-arylation utilising bulky ligands or bulky 4,5-substituents. ${ }^{6}$ Palladium catalysis has also been reported for this application. ${ }^{7}$ Chen et. al. have demonstrated the regioselective generation of $1,2,3-\mathrm{NH}-$ triazoles followed by subsequent arylation using one-pot multicomponent reactions starting from a variety of molecules. ${ }^{8,9,10}$ However, the scope of these $S_{N} A r$ reactions was limited to electron poor substrates.

Syntheses from bis(arylhydrazones) $\mathbf{3}$ can proceed via acid catalysed rearrangement to 1,2,3-triazolium-1aminides. Subsequent photolysis or reduction with carbon disulfide ${ }^{11}$ and hydrogen sulfide ${ }^{12}$ yield the triazole. Butler et. al. favoured oxidation to 1,2,3-triazolium-1aminides and subsequent reduction to triazoles using lead oxide and phosphorous trichloride respectively. ${ }^{13}$ Most recently, Guru et. al. have shown efficient and regiospecific copper catalysed formation of triaryl 1,2,3or 1,2,4-triazoles from arylhydrazones under aerobic conditions. $^{14}$

In an effort to synthesize pyrazoline adducts $\mathbf{8}$ to serve as probes for the intracellular visualisation of alkene-tagged systems 7, we unexpectedly isolated 2,4,5-triaryl 1,2,3triazoles 9 from 2,5-diaryl tetrazoles 5 (Scheme 2). Previous accounts had reported the formation of tetrazine $\mathbf{1 0}$ from the dimerisation of the nitrile imine intermediate $\mathbf{6}$, in contrast to the triazoles isolated in the current study. ${ }^{15,16}$

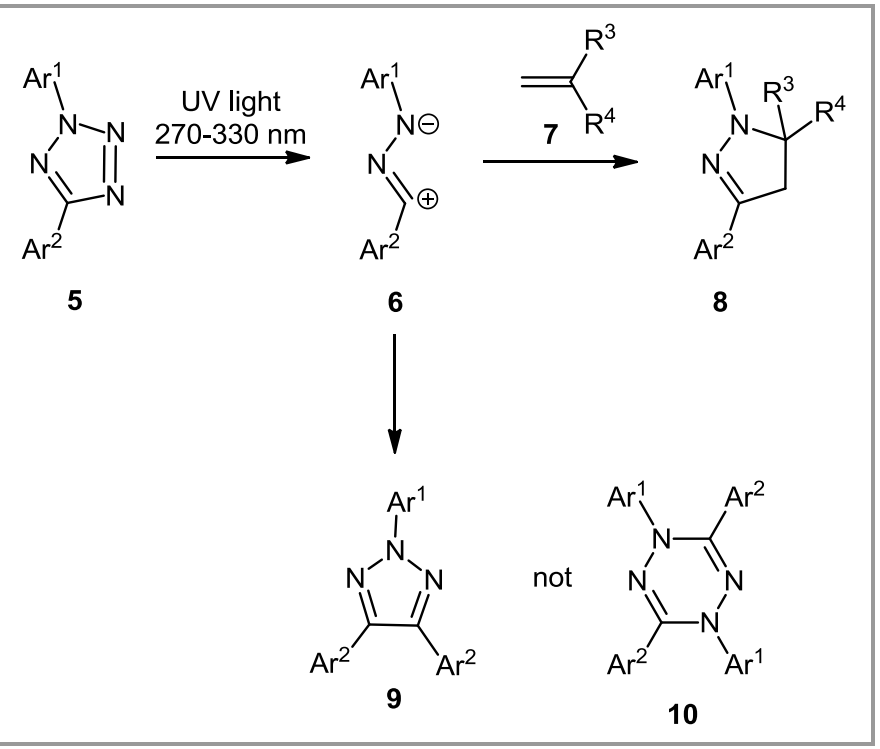

Scheme 2 Formation of 2,4,5-triaryl 1,2,3-triazoles as a by-product of photochemical pyrazoline synthesis 
A survey of the literature revealed few examples of converting 2,5-diaryl tetrazoles to triazoles under photochemical conditions. ${ }^{17,18}$ Using recently developed methodology for the copper catalysed synthesis of 2,5diaryl tetrazoles ${ }^{19}$ we decided to investigate the scope of this reaction. Accordingly, 2,5-diaryl tetrazoles 5a-q were prepared from 5-aryl NH-tetrazoles $\mathbf{1 1}$ and aryl boronic acids $\mathbf{1 2}$ in $49-93 \%$ yield (Table 1) as substrates for the study. ${ }^{19}$

Table 1 Synthesis of 2,5-diaryl tetrazoles

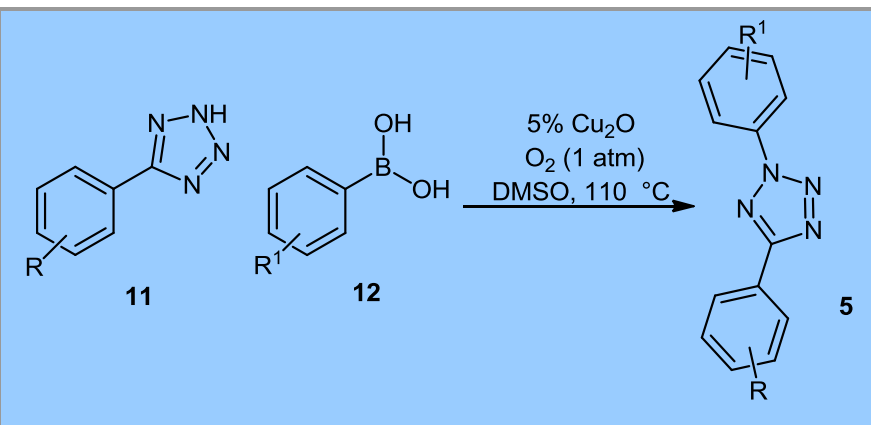

\begin{tabular}{|c|c|c|c|c|}
\hline Entry & $\mathrm{R}$ & $\mathrm{R}^{1}$ & Yield/ \% & Time/ h \\
\hline $5 a$ & $\mathrm{H}$ & $\mathrm{H}$ & 86 & 6 \\
\hline $5 b$ & $p-\mathrm{Cl}$ & $\mathrm{H}$ & 64 & 72 \\
\hline $5 c$ & $m-\mathrm{Cl}$ & $\mathrm{H}$ & 84 & 24 \\
\hline $5 d$ & $o-\mathrm{Cl}$ & $\mathrm{H}$ & 85 & 24 \\
\hline $5 e$ & $p$-OMe & $\mathrm{H}$ & $-{ }^{\mathrm{a}}$ & - \\
\hline $5 f$ & $\mathrm{H}$ & $p$-Me & 93 & 6 \\
\hline $5 \mathrm{~g}$ & $\mathrm{H}$ & $p$-OMe & $-{ }^{a}$ & - \\
\hline $5 \mathrm{~h}$ & $\mathrm{H}$ & $m$-OMe & 77 & 16 \\
\hline $5 \mathrm{i}$ & $\mathrm{H}$ & $o$-OMe & 49 & 16 \\
\hline $5 \mathrm{j}$ & $\mathrm{H}$ & $p-\mathrm{NH}_{2}$ & $-b$ & - \\
\hline $5 \mathrm{k}$ & $\mathrm{H}$ & $p-\mathrm{NH}(\mathrm{CO}) \mathrm{Me}$ & $-c$ & - \\
\hline 51 & $\mathrm{H}$ & $p-\mathrm{CO}_{2} \mathrm{Et}$ & 75 & 24 \\
\hline $5 \mathrm{~m}$ & $\mathrm{H}$ & $m-\mathrm{CN}$ & 60 & 6 \\
\hline $5 n$ & $\mathrm{H}$ & $p-\mathrm{NO}_{2}$ & 55 & 24 \\
\hline 50 & $p$-OMe & $p$-OMe & $-{ }^{\mathrm{a}}$ & - \\
\hline $5 p$ & $p-\mathrm{Cl}$ & $p$-OMe & 70 & 22 \\
\hline $5 q$ & $p-\mathrm{SO}_{2} \mathrm{NMe}_{2}$ & $p$-OMe & 79 & 16 \\
\hline
\end{tabular}

${ }^{\mathrm{a}}$ Commercially available

${ }^{\mathrm{b}}$ Synthesised by reduction of tetrazole $5 \mathrm{n}(86 \%)$

${ }^{\mathrm{c}}$ Synthesised by acetylation of tetrazole $5 \mathrm{j}(92 \%)$

With a range of suitably functionalised tetrazole systems in hand, we conducted a solvent screen; a number of which were tolerated in the reaction, including: DCM, MeCN, TBME, 2-MeTHF, EtOAc, toluene and DMF. However, DMSO failed to produce any reaction due to inhibition of nitrile imine formation. Further experimentation revealed that a mixture of 2-MeTHF:isopropyl alcohol $(1: 1 \mathrm{v} / \mathrm{v})$ was a suitable environmentally sustainable solvent system for the reaction. ${ }^{20}$

Tetrazoles 5a-q were irradiated with a UVB lamp (270$330 \mathrm{~nm}$ ) in 2-MeTHF:isopropyl alcohol under atmospheric conditions, until all starting material had been consumed. The triazole products were isolated by chromatography and the results shown in Table 2 provide insight into the effects of substituents on the reaction.

Tetrazole 5a was chosen as a baseline for comparison of substituent effects and gave triazole 9a in $19 \%$ yield.
Initial substituent effects were investigated with $C$-aryl substitution (Entries 9b-9e). Electron donating substituents appeared to improve yields slightly, relative to electronically neutral 9a. Substitution in the meta and para positions were tolerated; however, $o-\mathrm{Cl}$ substitution failed to yield triazole 9d. It was reasoned that this substitution was not tolerated due to steric effects in the nitrile imine intermediate.

\section{Table 2 Photochemical synthesis of 2,4,5-triaryl 1,2,3-triazoles}

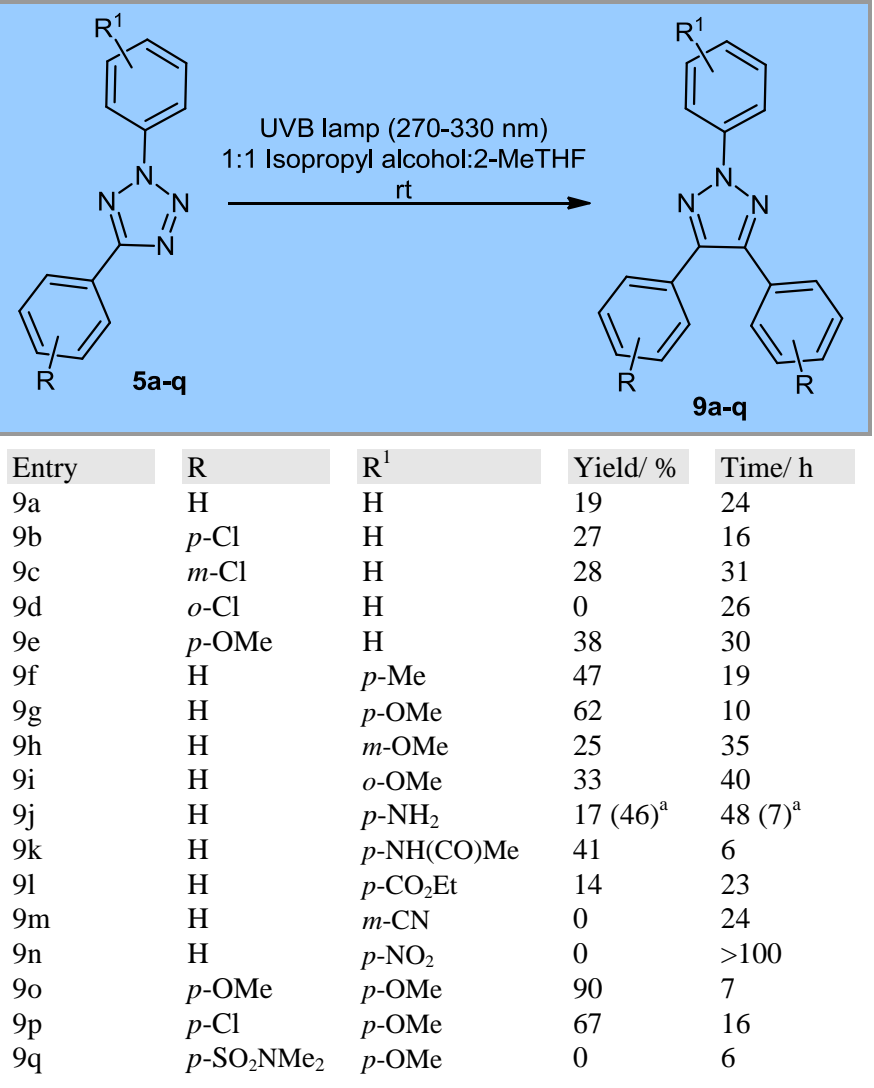

${ }^{\mathrm{a}}$ Isopropyl alcohol:2-MeTHF solvent (5x volume)

We then investigated the electronic effect of substituents on the $N$-aryl ring (Entries 9f-9k). In general, addition of electron donating groups favoured formation of the desired triazoles in significantly improved yields, particulary in the para position. Interestingly, ortho substitution is also tolerated, albeit in moderate yield. Substitution with $p-\mathrm{NH}_{2}$ was expected to give excellent reactivity; however, triazole $\mathbf{9 j}$ could only be isolated in $17 \%$ yield. Conducting the reaction under more dilute conditions gave an improved yield of $46 \%$ due to reduced byproduct formation and improved solubility of tetrazole $\mathbf{5 j}$. However, the role of concentration was not explored further in the current study. Instead, the reactive aniline moiety was protected as an acetamide derivative to afford triazole $9 \mathbf{k}$ in an improved yield of $41 \%$.

As expected, electron deficient $N$-aryl substituents were poorly tolerated. Of these, only $p-\mathrm{CO}_{2} \mathrm{Et}$ tetrazole 5l yielded the desired triazole and in a lower yield than for electronically neutral tetrazole 5a. Photo-activation of $p$ - 
$\mathrm{NO}_{2}$ tetrazole 5n was inefficient, with starting material predominating after irradiaton for 100 hours, and no discernible product evident after this time. Incorporation of a $m$-CN in tetrazole $\mathbf{5 m}$ group did not afford the expected triazole 9m. Instead, isopropyl- $N$-(3cyanophenyl) benzo-hydrazonate $\mathbf{1 3}$, formed by trapping of the nitrile imine $\mathbf{6 m}$ with isopropyl alcohol, was isolated as the major product with a yield of $54 \%$ (Scheme 3). Such nucleophilic quenching reactions have been reported previously. ${ }^{21,22}$ Repeating the reaction in ethyl acetate also failed to yield the desired product, presumably due to poor reactivity resulting from the electron withdrawing $\mathrm{CN}$ substituent. It should be noted that trapping of the nitrile imine was not observed with the more reactive tetrazole substrates.

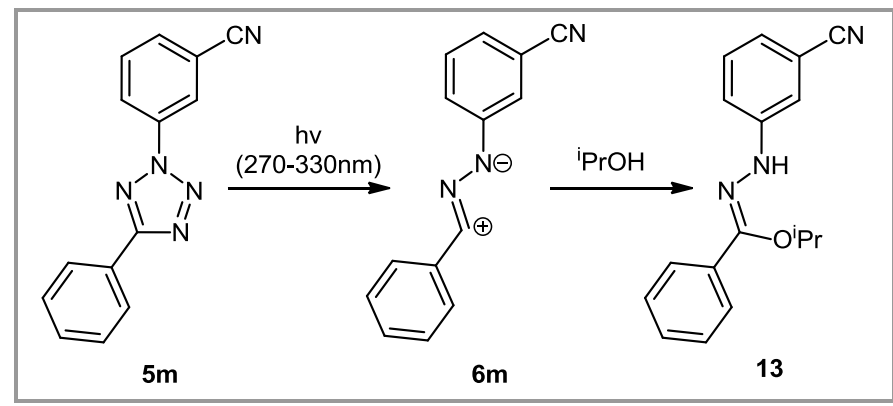

Scheme 3 Trapping of nitrile imine $\mathbf{1 3}$ by isopropyl alcohol

Finally, the observed trends in reactivity were combined when studying triazoles 9o-9q. As predicted, combining an electron rich $\mathrm{N}$-aryl ring with electron donating groups on the $C$-aryl ring gave significant improvements in yields. However, the electron withdrawing effects of a sulfonamide moiety could not be surmounted.

Interestingly, during the synthesis of triazole 9p a precipitate was formed and, when isolated, Wanzlick dimer $\mathbf{1 5}$ was obtained in $57 \%$ yield instead of the expected triazole (Scheme 4). Previously, photochemical formation of this intermediate had only been observed spectroscopically. ${ }^{17}$ Further exposure to UV light yielded the desired product by rearrangement to 1,2,3triazolium-1-aminide 16 and $\mathrm{N}-\mathrm{N}$ bond cleavage.

We suggest that formation of this Wanzlick dimer may occur through the carbenic resonance form 14 of the nitrile imine; which explains the tolerance of $O$ subtituents on the $N$-aryl ring, but not the $C$-aryl ring. ${ }^{23}$. Based on these observations, we also suggest that the tetrazine by-products previously reported during pyrazoline syntheses $^{15,16}$ may have been Wanzlick dimers, as their NMR profile would appear similar. Furthermore, we did not observe tetrazine by-products during our syntheses of pyrazoline adducts.

Having investigated the synthesis of 2,4,5-triaryl 1,2,3triazoles, we then sought to determine if $C$-heterocyclic or $C$-alkyl groups could be tolerated (Scheme 5 ).

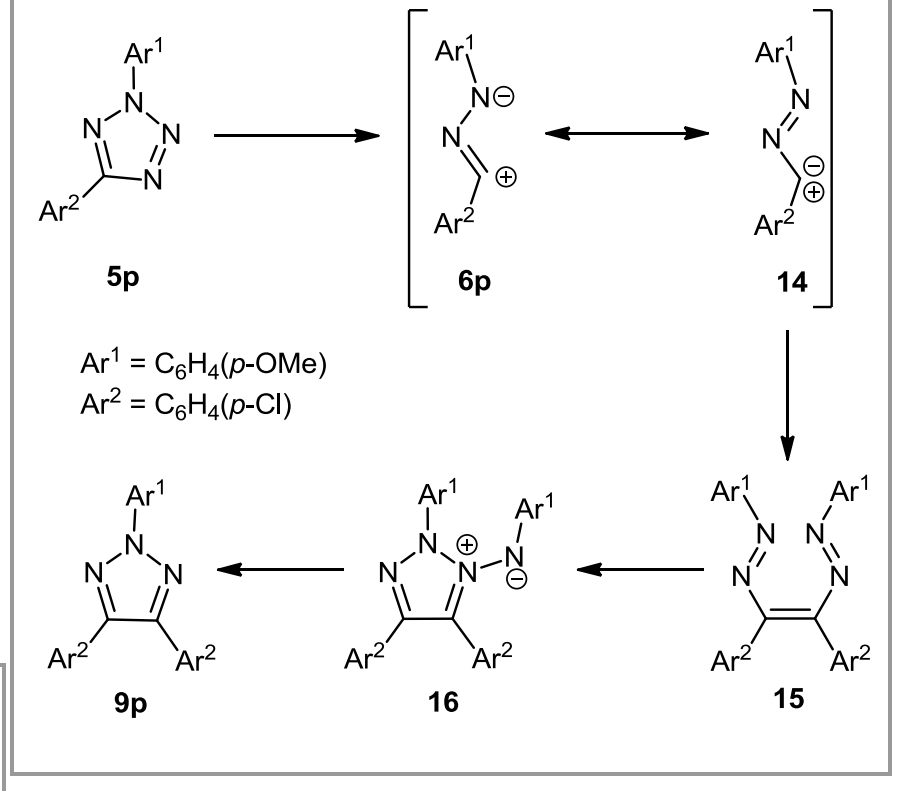

Scheme 4 Mechanism of N2-aryl 1,2,3-triazole formation

Commercially available 4-(5-ethyl- $2 \mathrm{H}$-tetrazol-2yl)aniline 17 was irradiated to give triazole 19 in a modest $23 \%$ yield. In this case, masking the aniline with an acetamide moiety failed to improve the yield, indicating that $C$-alkyl groups are unfavourable. This could be attributed to a less stable carbocation in the nitrile imine intermediate, compared to $C$-aryl systems, resulting in a complex mixture of products. When irradiating $C$ morpholine tetrazole $\mathbf{2 1}$ we were surprised to observe efficient conversion to 3-morpholine indazole 22. Such transformations have been observed previously using more forcing conditions such as high temperature. ${ }^{25,26}$

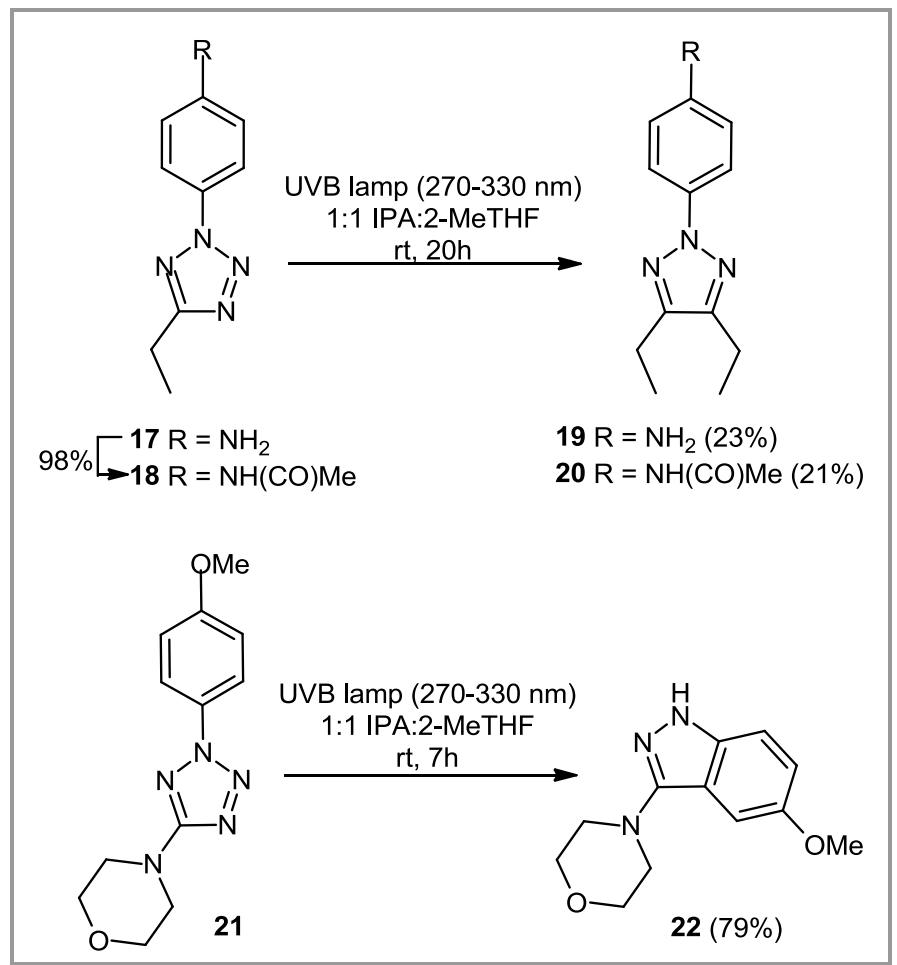

Scheme 5 Synthesis of a N2-aryl 4,5-dialky 1,2,3-triazole and unexpected formation of substituted indazoles 
Finally, we wished to investigate if other sources of nitrile imine intermediates could also yield 2,4,5trisubtituted 1,2,3-triazoles. Interestingly, formation of tetrazine products via nitrile imine intermediates had been reported by Molteni et. al. from $C$-acyl, $N$-Aryl hydrazonyl chlorides. ${ }^{24}$ To determine if $C$-aryl substitution would instead yield triazole products we synthesised hydrazonoyl chloride 23 and generated nitrile imine $\mathbf{6 f}$ using sodium hydroxide. Gratifyingly, the main product of the reaction was triazole $9 f$ ( $29 \%$ yield, unoptimised conditions) as confirmed by comparison to the previously obtained product (Scheme 6).

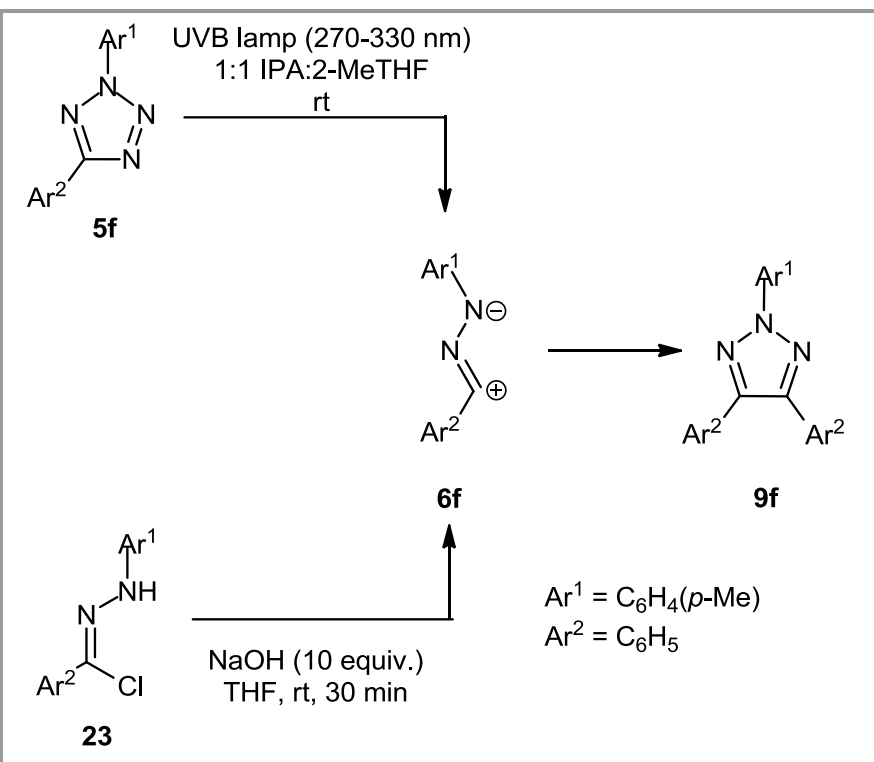

Scheme 6 Synthesis of triazole 9f from 2,5-diaryl tetrazoles or hydrazonyl chlorides

In conclusion, we have demonstrated the photochemical synthesis of a number of 2,4,5-triaryl 1,2,3-triazoles in two steps under mild conditions. Although the reaction shows strong dependence on substituent effects, with electron donating groups giving the best reactivity, we believe the current approach offers efficient access to this useful heterocyclic scaffold. This reaction is therefore complementary to other synthetic routes and alternative sources of nitrile imines can also be adopted. The synthesis of N2-aryl 4,5-dialkyl 1,2,3-triazole and 3substituted indazole systems was also shown to be possible using this methodology.

\section{Representative Example for the preparation of 2,5- diaryl tetrazoles: 5-phenyl-2-(p-tolyl)-2H-tetrazole (5f)}

A solution of $p$-tolyl boronic acid (1.86 g, $13.7 \mathrm{mmol}), 5$ phenyl tetrazole $(1.00 \mathrm{~g}, 6.84 \mathrm{mmol})$ and Copper(I) oxide $(5 \mathrm{~mol} \%, 0.049 \mathrm{~g}, 0.342 \mathrm{mmol})$ in DMSO $(30 \mathrm{~mL})$ was stirred under $\mathrm{O}_{2}(1 \mathrm{~atm})$ at $110^{\circ} \mathrm{C}$ for $6 \mathrm{~h}$. The reaction mixture was allowed to cool, diluted with ethyl acetate $(200 \mathrm{~mL})$ and washed successively with $1 \mathrm{M}$ $\mathrm{HCL}_{(\mathrm{aq})}$ solution $(30 \mathrm{~mL})$ and brine $(30 \mathrm{~mL})$ three times. The organic phase was separated, dried, and concentrat- ed in vacuo. Purification by flash column chromatography ( $\mathrm{Si}, 50 \mathrm{~g}, 0-10 \%$ EtOAc-cyclohexane, $60 \mathrm{mins}$ ) gave 5-phenyl-2-( $p$-tolyl)-2H-tetrazole $5 f(1.51 \mathrm{~g}, 93 \%)$ as a white solid. mp 103-104 ${ }^{\circ} \mathrm{C}$. IR $\left(\mathrm{cm}^{-1}\right): 1507,1448$, 1212, 1012. ${ }^{1} \mathrm{H}$ NMR $\left(400 \mathrm{MHz}, \mathrm{CDCl}_{3}\right): \delta_{\mathrm{H}}=8.26(\mathrm{dd}$, $J=2.0,8.1 \mathrm{~Hz}, 2 \mathrm{H}), 8.08(\mathrm{~d}, J=8.6 \mathrm{~Hz}, 2 \mathrm{H}), 7.57$ $7.47(\mathrm{~m}, 3 \mathrm{H}), 7.38(\mathrm{~d}, J=8.6 \mathrm{~Hz}, 2 \mathrm{H}), 2.46(\mathrm{~s}, 3 \mathrm{H})$ ppm. ${ }^{13} \mathrm{C}$ NMR $\left(101 \mathrm{MHz}, \mathrm{CDCl}_{3}\right): \delta_{\mathrm{C}}=165.1,139.9$, $134.8,130.5,130.2,128.9,127.3,127.0,120.0,119.8$, 77.3, 77.2, 77.0, 76.7, $21.2 \mathrm{ppm}$. HRMS (ESI $\left.{ }^{+}\right): \mathrm{m} / \mathrm{z}$ calcd for $\mathrm{C}_{14} \mathrm{H}_{13} \mathrm{~N}_{4}$ : 237.1135; found 237.1128.

Representative example for the preparation of $2,4,5$ trisubstituted 1,2,3-triazoles: 4,5-diphenyl-2-( $p$-tolyl)2H-1,2,3-triazole (9f)

A solution of 5-phenyl-2-(p-tolyl)-2H-tetrazole 5f (200 $\mathrm{mg}, 0.85 \mathrm{mmol})$ in 1:1 Isopropyl alcohol:2-MeTHF (10 $\mathrm{mL}$ ) was stirred under irradiation with a UVB lamp $(270-330 \mathrm{~nm})$ for $19 \mathrm{~h}$. The reaction mixture was concentrated in vacuo and the residue purified by reverse phase chromatography ( $\mathrm{Si} \mathrm{C}_{18}, 50-95 \% \mathrm{MeCN}: \mathrm{H}_{2} \mathrm{O}$, $\mathrm{HCO}_{2} \mathrm{H}$ modifier, 30 mins) to give 4,5-diphenyl-2-( $p$ tolyl)-2 $\mathrm{H}$-1,2,3-triazole 9f (62 $\mathrm{mg}, 47 \%)$ as a brown gum. IR $\left(\mathrm{cm}^{-1}\right): 1510,1441,1268 .{ }^{1} \mathrm{H}$ NMR $(400 \mathrm{MHz}$, $\left.\mathrm{CDCl}_{3}\right): \delta_{\mathrm{H}}=8.10(\mathrm{~d}, J=8.6 \mathrm{~Hz}, 2 \mathrm{H}), 7.72-7.65(\mathrm{~m}, 4$ $\mathrm{H}), 7.43(\mathrm{dd}, J=1.9,4.9 \mathrm{~Hz}, 6 \mathrm{H}), 7.33(\mathrm{~d}, J=8.6 \mathrm{~Hz}, 2$ $\mathrm{H}), 2.45(\mathrm{~s}, 3 \mathrm{H}) .{ }^{13} \mathrm{C}$ NMR $\left(101 \mathrm{MHz}, \mathrm{CDCl}_{3}\right): \delta_{\mathrm{C}}=$ 145.7, 137.6, 137.3, 130.9, 129.8, 128.6, 128.6, 128.5, 127.1, 118.7, 21.1. HRMS $\left(\mathrm{ESI}^{+}\right): \mathrm{m} / \mathrm{z}$ calcd for $\mathrm{C}_{21} \mathrm{H}_{18} \mathrm{~N}_{3}$ : 312.1495 ; found 312.1496 .

\section{Acknowledgment}

We would like to thank The University of Strathclyde and GlaxoSmithKline for the financial support of this project.

\section{References}

(1) Hadd, M.A.; Nichelson, B.J.; Zhu, Z. WO 2005/000841A1, 2005.

(2) Hou, D.; Alam, S.; Kuan, T.; Ramanathan, M.; Lin, T.; Hung, M. Bioorg. Med. Chem. Lett. 2009, 19, 1022.

(3) Brockunier, L. L.; Parmee, E. R.; Ok, H. O.; Candelore, M. R.; Cascieri, M. A.; Colwell, L. F.; Deng, L.; Feeney, W. P.; Forrest, M. J.; Hom, G. J.; Macintyre, D. E.; Tota, L.; Wyvratt, M. J.; Fisher, M. H.; Weber, A. E. Bioorg. Med. Chem. Lett. 2000, 10, 2111.

(4) Yan, W.; Wang, Q.; Lin, Q.; Li, M.; Petersen, J. L.; Shi, X. Chem. Eur. J. 2011, 17, 5011.

(5) Maliakal, A.; Lem, G.; Turro, N. J.; Ravichandran, R.; Suhado-lnik, J. C.; DeBellis, A. D.; Wood, M. G.; Lau, J. J. Phys. Chem. A. 2002, 106, 7680. (b) Heller, H. J.; Blatttmann, H. R. Pure Appl. Chem. 1973, 36, 141.

(6) Liu, Y.; Yan, W.; Chen, Y.; Petersen, J. L.; Shi, X. Org. Lett. 2008, 10, 5389 .

(7) Ueda, S.; Su, M.; Buchwald, S. L. Angew. Chem. Int. Ed. 2011, 50, 8944.

(8) Zhang, Y.; Wang, D.; Wang, W.; Gao, T.; Wang, L.; Li, J.; Huang, G.; Chen, B. Synlett 2010, 11, 1617.

(9) Zhang, Y.; Li, X.; Li, J.; Chen, J.; Meng, X.; Zhao, M.; Chen, B. Org. Lett. 2012, 14, 26.

(10) Liu, X.; Li, X.; Chen, Y.; Wang, D.; Chen, J.; Chen, B. Asian J. Org. Chem. 2013, 212.

(11) Sukumaran, K. B.; Satish, S.; George, M. V. Tetrahedron 1974, $30,445$. 
(12) Butler, R.; O'Shea, D. J. Chem. Res. 1994, 350.

(13) Butler, R. N.; Hanniffy, J. M.; Stephens, J. C.; Burke, L. J. Org. Chem. 2008, 73, 1354.

(14) Guru, M. M.; Punniyamurthy, T. J. Org. Chem. 2012, 77, 5063.

(15) Wang, Y.; Vera, C. I. R.; Lin, Q. Org. Lett. 2007, 9, 4155.

(16) Wang, Y.; Song, W.; Hu, W. J.; Lin, Q. Angew. Chem. Int. Ed. Engl. 2009, 48, 5330.

(17) Meier, H.; Heinzelmann, W.; Heimgartner, H. Chimia, 1980, 34, 504-506.

(18) Claus, P.; Doppler, T.; Gakis, N.; Georgarakis, M.; Giezendanner, H.; Gilgen, P.; Heimgartner, H.; Jackson, B.; Märky, M.; Narasimhan, N. S.; Rosenkranz, H. J.;

Wunderli, A.; Hansen, H.-J.; Schmid, H. Pure Appl. Chem. 1973, 33, 339-362.

(19) Li, Y.; Gao, L.-X.; Han, F.-S. Chem. Commun. 2012, 48, 2719.

(20) a) Henderson, R. K.; Jiménez-González, C.; Constable, D. J. C.; Alston, S. R.; Inglis, G. G.; Fisher, G.; Sherwood, J.; Binks, S. P.; Curzons, A. D. Green Chem. 2011, 13, 854. b) Pace, V.; Hoyos, P.; Castoldi, L.; Domínguez de María, P.; Alcántara, A. R. ChemSusChem 2012, 5, 1369-1379. c) Yilgor, E.; Ekin Atilla, G.; Ekin, A.; Kurt, P.; Yilgor, I. Polymer 2003, 44, 7787-7793.

(21) Meier, H.; Heinzelmann, W.; Heimgartner, H. Helvetica Chimia Acta, 1985, 68, 1283.

(22) Abu Thaher, B.; Zahra, J.; El-Abadelah, M. M.; Voelter, W. Z Naturforsch. 2004, 59b, 930.

(23) Böhm, V. P. W.; Herrmann, W. A. Angew. Chem. Int. Ed. 2000, 39, 4036-4038.

(24) Molteni, G.; Orlandi, M.; Broggini, G. J. Chem. Soc. Perkin Trans. 1 2000, 3742.

(25) Wentrup, C.; Benedikt, J. J. Org. Chem. 1980, 45, 14071409.

(26) Wentrup, C.; Damerius, A.; Reichen, W. J. Org. Chem. 1978, 43, 2037-2041.

(27) Patel, H.; Vyas, K.; Pandey, S.; Fernandes, P. Tetrahedron 1996, 52, 661-668. 
Please place the graphical abstract and short title of the article here. The short title will be used as a running header. Manuscript submission checklist

- Statement of significance of work.

- Full mailing address, telephone and fax numbers, and email address of the corresponding author.

- Paper save as a PDF file.

- Original Word file.

- Original graphic files.

- Graphical abstract. 